\title{
Endospanin 1 Determines the Balance of Leptin-Regulated Hypothalamic Functions
}

\author{
Clara Roujeau Ralf Jockers Julie Dam \\ Inserm U1016, CNRS UMR 8104, Institut Cochin, Université Paris Descartes, Sorbonne Paris Cité, Paris, France
}

\author{
Keywords \\ Leptin receptor - Trafficking - Cell surface receptors · Biased \\ signaling $\cdot$ Leptin resistance $\cdot$ Obesity - Diabetes
}

\begin{abstract}
Endospanin 1 (Endo1), a protein encoded in humans by the same gene than the leptin receptor $(\mathrm{ObR})$, and increased by diet-induced obesity, is an important regulator of ObR trafficking and cell surface exposure, determining leptin signaling strength. Defective intracellular trafficking of the leptin receptor to the neuronal plasma membrane has been proposed as a mechanism underlying the development of leptin resistance observed in human obesity. More recently, Endo1 has emerged as a mediator of "selective leptin resistance." The underlying mechanisms of the latter are not completely understood, but the possibility of differential activation of leptin signaling pathways was suggested among others. In this respect, the expression level of Endo1 is crucial for the appropriate balance between different leptin signaling pathways and leptin functions in the hypothalamus and is likely participating in selective leptin resistance for the control of energy and glucose homeostasis.
\end{abstract}

() 2018 S. Karger AG, Basel
Obesity is one of the major issues of public health, with more than 100 million obese children and 600 million obese adults worldwide in 2015 [1]. An imbalance between energy intake and expenditure triggers an excess of fat mass leading to obesity. This chronic disease is considered as a risk factor for several pathologies such as type 2 diabetes (T2D), cardiovascular diseases and cancers. Innovative therapies to reduce food intake (FI) and/or to increase energy expenditure are still under investigation. In 1994, the discovery of leptin raised great hope to combat the obesity epidemic [2]. Indeed, the obese and diabetic phenotype of rodents and humans with congenital leptin deficiency can be reversed by administration of recombinant leptin mainly by decreasing FI and body weight (BW) [3-5]. This was the early demonstration that leptin is an anorectic hormone critical to maintain energy and glucose homeostasis. Intriguingly, for the vast majority of obese human subjects, endogenous leptin has lost its capacity to promote its anorectic actions giving rise to the concept of "leptin resistance". Understanding the mechanisms responsible for leptin resistance is crucial to identify the molecular causes of obesity that can be targeted for therapeutic interventions. Leptin resistance
Dr. Julie Dam
22, rue Méchain
FR-75014 Paris (France)
E-Mail julie.dam@inserm.fr 
could arise from an alteration of multiple mechanisms of which the modification in leptin receptor (ObR) exposure at the plasma membrane was initially suggested by us and others. In this context, we identified endospanin 1 (Endo1) as a novel regulator of ObR/leptin functions. In this review, we will particularly focus on ObR activation in the hypothalamus and leptin resistance, highlighting ObR regulation by Endol.

\section{Leptin, a Crucial Hormone Involved in the Central Regulation of Energy and Glucose Homeostasis}

\section{Central Action of Leptin through Its Receptor ObRb}

Leptin is a peptidic hormone mainly secreted by the white adipose tissue, in proportion to its fat mass [6]. The effects of leptin on the control of BW and FI are centrally mediated through the binding to the long receptor isoform ObRb, highly expressed in hypothalamic nuclei such as the arcuate nucleus (ARC) [7]. The ARC constitutes a major center for the integration of leptin action (among other metabolic signals) by its close proximity to the median eminence, a circumventricular organ that mediates specific and active leptin entry into the mediobasal hypothalamus [8]. The ARC is mainly composed by two distinct neuronal populations, namely the anorectic POMC/ CART and the orexigenic AgRP/NPY neurons. Both populations express $\mathrm{ObRb}$ and are activated or inhibited by leptin, respectively $[9,10]$. These first-order neurons project toward and regulate second-order neurons located in other hypothalamic nuclei, such as ventromedial, dorsomedial, lateral and paraventricular nuclei, or in extrahypothalamic areas, such as anterior subdivisions of the bed nucleus of the stria terminalis and paraventricular thalamic nucleus [11]. Interconnections between these nuclei allow a fine tuning of the metabolic responses to maintain energy and glucose homeostasis [12]. Those hypothalamic nuclei, which express $\mathrm{ObRb}$ [13], also respond directly to intranuclear injection of leptin [14-17].

Beyond the hypothalamic regions, $\mathrm{ObRb}$ was found to be expressed in other brain areas such as several thalamic nuclei, cerebellum, choroid plexus, hippocampus, nucleus tractus solitarius, ventral tegmental area and others $[13,18,19]$. Leptin-mediated activation of neurons in the nucleus tractus solitarius, the area postrema $[20,21]$ as well as the ventral tegmental area $[22,23]$ also participates in the maintenance of energy balance. More recently, multiple hypothalamic glial cell types have been identified to participate actively in the leptin-mediated control of energy balance $[8,24,25]$.

Hypothalamic Endospanin 1 Dissociates

Obesity from Type 2 Diabetes
Leptin Signaling Pathways in the Hypothalamus

$\mathrm{ObRb}$ is a type I cytokine receptor characterized by a transmembrane portion, an extracellular domain required for leptin binding, and a long cytosolic tail which binds the Janus tyrosine kinase 2 (JAK2). Leptin binding triggers a conformational change and an oligomerization of the receptor [26, 27], followed by activation of the JAK2/signal transducer and activator of transcription 3 (STAT3) pathway regulating the hypothalamic expression of anorectic or orexigenic neuropeptides [28]. s/s mice, with a mutation of ObRb preventing STAT3 activation, are hyperphagic and obese, while glucose homeostasis is relatively maintained compared to $d b / d b$ mice (total absence of ObRb) [28-30]. This suggests that leptin-induced JAK2/STAT3 signaling is required for the control of energy balance and that other pathways are necessary for the leptin-mediated regulation of glucose homeostasis. Among them, the phosphatidylinositide 3-kinase $(\mathrm{PI} 3 \mathrm{~K}) /$ protein kinase $\mathrm{B}$ (AKT) pathway is triggered by leptin via the recruitment of the insulin receptor substrate via JAK2 on ObRb [31]. The leptin-mediated PI3K/AKT pathway in the hypothalamus is involved in the control of glucose homeostasis, notably by improving hypothalamic and muscle insulin sensitivity and thus promoting glucose uptake and fatty acid $\beta$-oxidation [32, 33]. Leptin also regulates other signaling pathways in the hypothalamus to regulate energy metabolism [34-36], while finetuning of leptin signaling occurs through several negative feedback mechanisms [37-39]. Distinct leptin signaling pathways are also crucial for the developmental outcome of hypothalamic feeding circuits directing the formation of NPY and POMC projections [40].

\section{Central Leptin Resistance Associated with Obesity}

\section{Concept and Molecular Mechanisms of Leptin \\ Resistance}

More than $95 \%$ of obesity cases are defined as multifactorial with a marked influence of environmental factors and without monogenic mutation on leptin/ObR genes [41]. On the contrary, most obese patients display high levels of plasma leptin, in proportion to their excessive adiposity $[6,42]$. This hyperleptinemia is however unable to restore normal BW, suggesting that these patients are "insensitive" or "resistant" - at least partially [43] - to the anorectic effects of endogenous leptin. They are also insensitive to the administration of exogenous leptin, which does not trigger any physiological response (absence of decrease in FI or BW), or cellular effect either

Neuroendocrinology 2019;108:132-141 
(no induction of STAT3 phosphorylation in neurons) [44], with the exception of obese patients with congenital leptin deficiency. The concept of leptin resistance is therefore defined by the inability of obese patients to respond to high levels of endogenous and exogenous leptin [45]. Prevention and/or reversal of leptin resistance constitute a major challenge in obesity research. Understanding the precise molecular basis for leptin resistance must help to design efficient therapeutic strategies to restore leptin sensitivity [46]. Several mechanisms have been identified to trigger central leptin resistance. Defects in leptin transport into the hypothalamus have been reported in high fat diet (HFD)-induced obese (DIO) rodents as well as in obese patients [8, 47-49]. An impairment of hypothalamic leptin signaling is critical in the development of leptin resistance and may arise from an alteration of multiple mechanisms, such as overexpression of inhibitors of leptin signaling $[50,51]$, central chronic inflammation $[52,53]$ and endoplasmic reticulum stress [54]. We and others previously suggested that a defective ObR trafficking could also lead to a decrease in leptin sensitivity [55, 56].

Decreased ObR Localization at the Plasma Membrane as a Mechanism of Leptin Resistance

The amount of ObR localized at the cell surface is determined by the constant balance between synthesis, transport to the plasma membrane, internalization, recycling to the plasma membrane, degradation and also the proteolytic cleavage of the extracellular domain. ObR are mainly retained in the Golgi, trans-Golgi network and endosomes, whereas the surface receptor undergoes permanent constitutive endocytosis, independent of leptin stimulation, leading to lysosomal degradation without apparent recycling [57]. These processes result in short receptor half-life (less than $2 \mathrm{~h}$ ) and in low levels of both ObRa and ObRb isoforms at the cell surface (5-20\%) [57, 58]. The level of 5-20\% of ObR at the plasma membrane does not constitute the maximal activation capacity of leptin signaling. We reported that increasing ObR cell surface exposure by 2 -fold is able to increase leptin-induced STAT3 activation [56]. In line with this, since leptin deficient $o b / o b$ mice are more sensitive to leptin, it is conceivable that $o b / o b$ mice harbor more ObR at the plasma membrane. Whether ObR half-life changes according to physiological conditions (obesity, fasting, ageing...) is not known and would need further investigation. We and others suggest that a sufficient amount of ObRb at the plasma membrane, i.e. necessary to efficiently regulate energy balance, is however crucial for neuronal leptin sensitivity due to the membrane impermeability of leptin and to the high level of intracellular retention of the receptor. An alteration of ObRb intracellular trafficking should impair its cell surface expression, thus decreasing neuronal sensitivity to leptin. A network of critical regulators controlling ObR surface expression in hypothalamic neurons has recently been identified by us and others (Endo1, Bardet-Biedl syndrome, BBS, proteins or proteins of the ubiquitination complex, metalloproteinases), assessing their importance in the central regulation of energy metabolism and their participation in the development of leptin resistance (see below).

\section{Endo1, a Partner of ObRb Involved in the Control of Energy and Glucose Homeostasis}

\section{Endo1 Regulates ObR Cell Surface Localization and Energy Balance}

In the search for new molecular actors contributing to central leptin resistance, we previously identified Endo1 (also known as Ob-RGRP or LEPROT), as an important regulator of leptin function. Endol is a small protein with 4 transmembrane domains, encoded in humans by the same gene as $\mathrm{ObRb}$ via alternative splicing, but without amino acid sequence similarity with the receptor $[59,60]$. Besides the genetic link, Endo1 and ObRb display similar expression profiles, in particular in the hypothalamus, and are located in similar intracellular compartments (Golgi, trans-Golgi and late endosomes) [61], suggesting a functional interrelationship. We have shown that Endo 1 interacts with $\mathrm{ObRb}$, traps the receptor inside the cell and directs it from endosomes to lysosomes for degradation [61] (Fig. 1a, 2). Overexpression of Endo1 reduces ObRb exposure at the plasma membrane $[56,61]$. In contrast, the silencing of Endo1 decreases the lysosomal degradation of $\mathrm{ObRb}$ in favor of its recycling to the plasma membrane, thus increasing ObRb surface exposure $[56,61]$. The silencing of Endo1 therefore increases the leptin-induced signaling strength and leads to an improvement of STAT3 phosphorylation $[56,62]$. We observe that the expression of Endo1 is increased in the hypothalamic ARC of obese mice after an HFD, indicating that, in the pathogenesis of obesity, the Endol trafficking protein participates in restricting the number of ObRb receptors accessible to leptin, and contributes to leptin resistance [62] (Fig. 2a, b). Thus, by decreasing Endo1 expression specifically in the ARC (with Endo1-shRNA expressing lentiviral vectors), the development of obesity after an HFD was prevented [56] and corrected [62] in lean or obese 


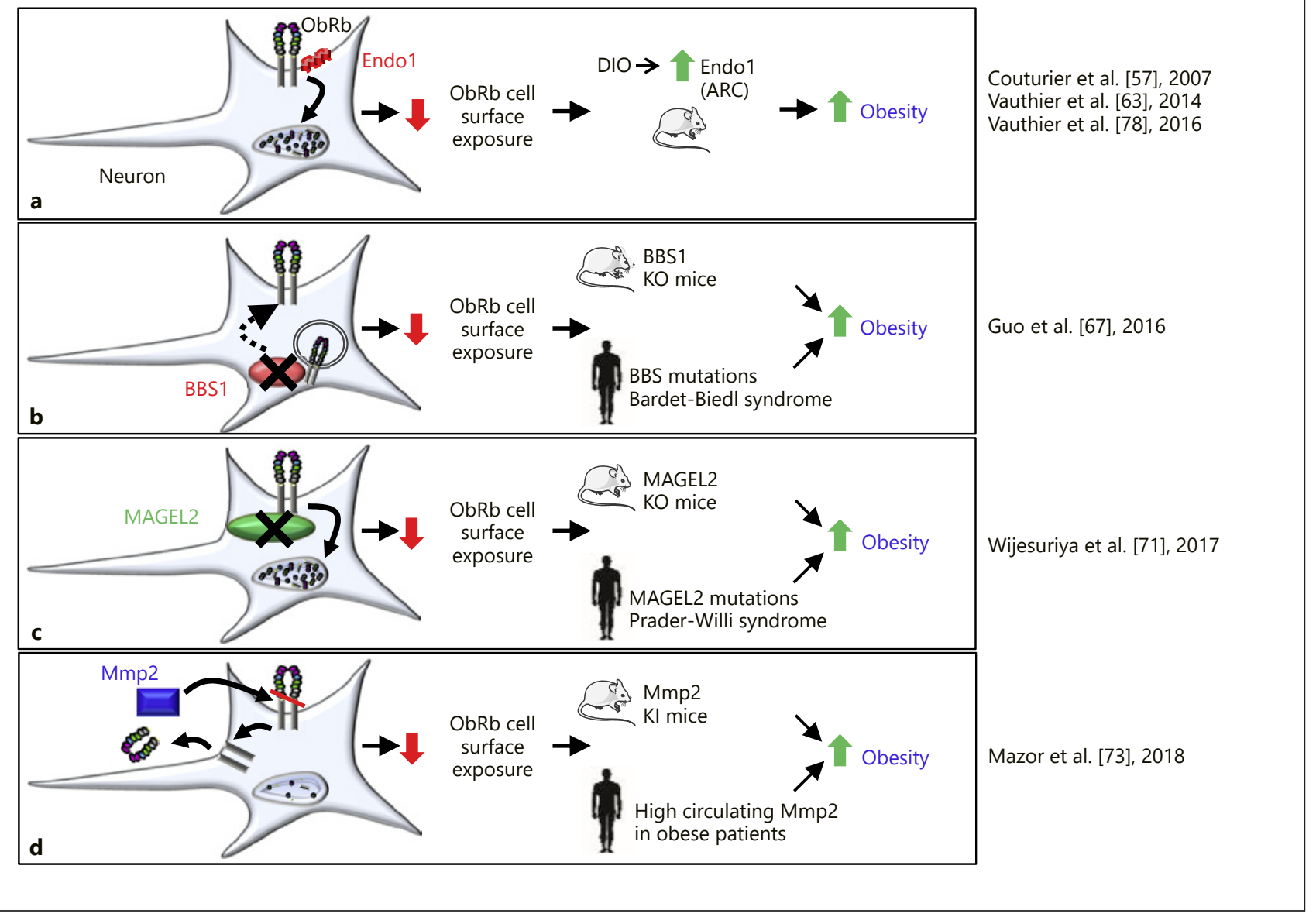

Fig. 1. The alteration of the neuronal surface exposure of ObRb is associated with the development of obesity. a Endol increases endocytosed $\mathrm{ObRb}$ degradation by interacting and targeting the receptor to lysosomes. HFD-induced obesity (DIO) increases Endo1 expression in the hypothalamic ARC. This decreases the pool of $\mathrm{ObRb}$ at the neuronal cell surface accessible to leptin and contributes to the development of obesity. $\mathbf{b}$ BBS1 transports ObRb to the neuronal plasma membrane by interacting with the receptor. Silencing BBS1 proteins impairs the trafficking of ObRb to the plasma membrane leading to central leptin resistance. Deletion of the bbs1 gene in the mediobasal hypothalamus causes obesity in mice and provides a novel mechanism for the development of obesity in

mice, respectively (Fig. 2a-c). Sustained BW loss was accompanied by decreased FI and fat mass as well as an amelioration of blood lipid parameters in Endo1-silenced mice and was associated with the enhancement of the leptin-induced STAT3 pathway in the ARC [56, 62].

\section{Cell Surface Localization of ObR and Human Obesity}

More recently, further studies have confirmed that the localization of ObR at the cell surface could account for patients with BBS. c MAGEL2 and RNF41 are part of ubiquitination complexes interacting with $\mathrm{ObRb}$ and controlling ObRb sorting and degradation. Mutations in MAGEL2 impair the MAGEL2mediated increase in ObR cell surface, providing a molecular mechanism for the obesity of patients with Prader-Willi syndrome similarly to MAGEL2 KO mice. d The matrix metalloproteinase 2 (Mmp2) cleaves the extracellular domain of ObRb. HFD-induced obesity increases Mmp2 activation in the hypothalamus of mice while obese patients display high plasma levels of Mmp2. Mmp2mediated cleavage of ObRb prevents leptin binding and signaling, promoting leptin resistance and obesity.

the obese phenotype observed in two human genetic diseases. Other regulators of intracellular ObR trafficking, such as the BBS proteins and proteins of the ubiquitination complex, have recently been identified to be involved in the pathogenesis of obesity. This highlights the importance of the very fine regulation of ObR localization at the plasma membrane as a critical factor in the development of obesity (Fig. 1). 


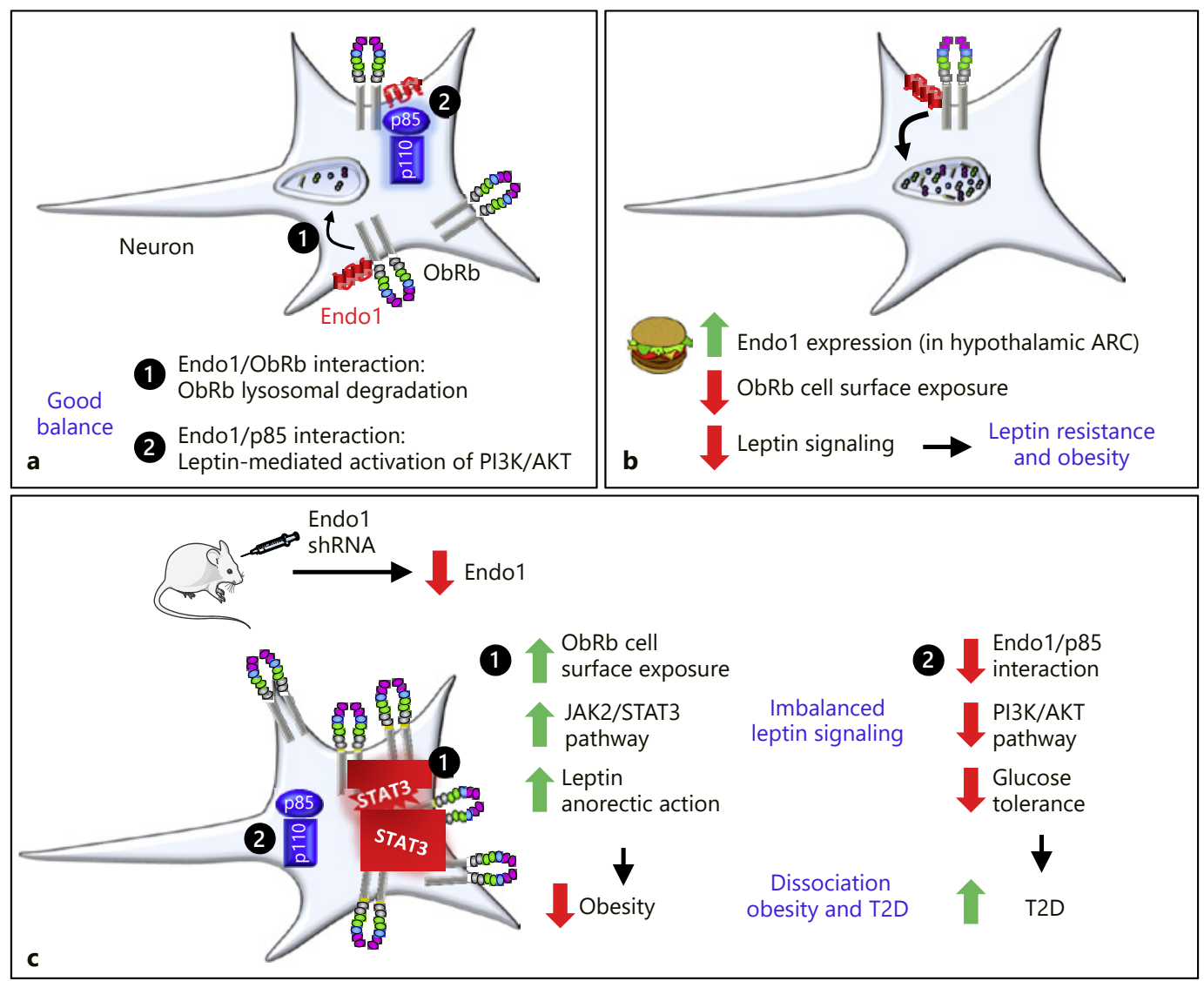

Fig. 2. Endospanin 1 (Endo1), mediator of biased leptin signaling, determines the dissociation between obesity and type 2 diabetes (T2D). a In physiological conditions, Endol interacts with $\mathrm{ObRb}$ and retains it in intracellular compartments increasing its lysosomal degradation. In addition, Endo1, by interacting with p85, the regulatory subunit of PI3K (p85-p110), is required for the leptin-induced PI3K/AKT pathway. b In a pathological context induced by HFD, Endol expression is increased in the hypotha-

BBS is an autosomal recessive, highly pleiotropic disorder in which obesity is a predominant feature [63]. Eight BBS proteins including BBS1, BBS2 and BBS4 form a stable complex, called BBSome, which transports proteins such as receptors to the primary cilium and possibly to other membrane compartments [63]. The primary cilium of hypothalamic neurons plays a vital role in the detection of metabolic signals [63]. An intriguing relationship between ObR and primary cilium has been observed at two different levels: one being the regulation by leptin of primary cilium length critical for the maintenance of lamic ARC. The number of ObRb located at the plasma membrane of neurons is then decreased, leading to the development of leptin resistance and obesity. c Partial Endo1 knock-down in the ARC affects differentially leptin signaling pathways (increased JAK2/ STAT3 pathway vs. decreased PI3K/AKT pathway) owing to the dual function of Endo1 which regulates both ObRb trafficking and signaling. This imbalance between leptin signaling pathways triggers dissociation between obesity and T2D. energy balance $[64,65]$, the other being the importance of some BBSome proteins, such as BBS1 and BBS2, in the control of ObR localization at the cell surface of neurons, independently of the primary cilium. The BBSome proteins BBS1 and BBS2 have been shown to interact with $\mathrm{ObR}$ and to control its trafficking, thus regulating energy homeostasis. In contrast to Endo1 which retains ObR inside, BBS1 transports ObR to the neuronal plasma membrane $[66,67]$. The deletion of BBS1 specifically in ObRbexpressing neurons causes obesity in mice $[66,67]$. The defective ObR trafficking would account for the obese 
phenotype seen in patients harboring mutations in BBS genes with BBS (Fig. 1b).

Ubiquitination and deubiquitination generally regulate receptor cell surface exposure by affecting their degradation, internalization, and subsequent intracellular sorting. The interaction of ubiquitin ligase RNF41 with ObR and with deubiquitinase USP8 promotes the export of ObR to the plasma membrane, via the destabilization of the ESCRT-O endocytic machinery complex required for lysosomal degradation of cargos $[68,69]$. More recently, the identification of other regulators of ObR trafficking has been extended to necdin and MAGEL2 proteins, which assemble into ubiquitination complexes and act jointly with RNF41 to regulate ObR levels at the plasma membrane (Fig. 1c). The alteration of the latter by MAGEL2 and necdin mutations is proposed to elicit obesity in patients with Prader-Willi syndrome, characterized by hyperphagia and leptin insensitivity [70]. These mutations appear to alter the sorting and degradation of ObR by a dynamic ubiquitin-dependent pathway, thereby reducing the availability of $\mathrm{ObR}$ at the neuronal plasma membrane [70]. In agreement, POMC neurons from mice lacking MAGEL2 fail to depolarize in response to leptin [71].

The shedding of the ObR extracellular domain by the matrix metalloproteinase-2 (Mmp2) has recently been identified as a novel mechanism of decreased ObR activity in the hypothalamus, associated with obesity [72] (Fig. 1d). Mmp2, strongly activated upon HFD in the mouse hypothalamus, cleaves ObR, thus attenuating leptin signaling in mice. Inversely, hypothalamic Mmp2 deletion restores ObR expression and reduces weight gain [72]. Interestingly, in humans, increased plasma Mmp2 activity has been observed in obese patients compared to lean subjects $[73,74]$.

Overall these data reveal the importance of the network regulating the intracellular trafficking of ObR and its levels at the neuronal surface, for the correct maintenance of leptin binding and induction of leptin signaling along with preserving the fine-tuned action of the negative feedback regulators (SOCS3, PTP1B or TCPTP) of leptin signaling. An excessive activation of $\mathrm{ObRb}$, promoting an increased activity of the negative regulators, as well as an insufficient amount of ObRb at the plasma membrane should both favor the development of obesity. Indeed, in humans, a disturbance in the balance of cell surface ObR levels seems to lead to that outcome (Fig. 1). Similarly, multiple mutations in the gene encoding the MC4R melanocortin receptor result in intracellular MC4R neuronal retention, which can be rescued by chaperone molecules [75]. In a therapeutic search, we have

Hypothalamic Endospanin 1 Dissociates

Obesity from Type 2 Diabetes also identified chemical molecules capable of increasing the pool of ObR at the cell surface in order to reverse neuronal leptin resistance and obesity [76]. Such molecules may become useful for patients with Prader-Willi syndrome or Bardet-Biedl syndrome, likely characterized by a diminished neuronal ObR surface exposure.

\section{Central Endo1 Silencing Triggers Leptin Biased}

Signaling and Dissociates Obesity from T2D

Our work on Endo1 surprisingly raised another facet of Endo1 revealing the functional complexity of this trafficking regulator (Fig. 2). Intriguingly, despite the increase in ObR surface localization, leptin-induced activation of the PI3K/AKT pathway is greatly diminished in the absence of Endo1, unlike the enhanced STAT3 pathway [77]. This suggests an additional mechanism of action of Endo 1 on ObR signaling, independent of its effect on regulating the pool of $\mathrm{ObR}$ at the cell surface. In the signaling complex, Endo1, interacting with ObR and with p85, the regulatory subunit of $\mathrm{PI} 3 \mathrm{~K}$, is required to activate the PI3K pathway by leptin [77]. The alteration of the latter in the ARC disrupts the regulation of glucose homeostasis with ultimate development of T2D. In normal conditions, silencing Endo1 in the ARC of lean mice does not alter glucose homeostasis when mice are fed with a chow diet, but when challenged with a HFD, Endo1-silenced mice start to display alterations of glucose homeostasis without development of obesity [77]. When Endo1 is silenced in obese mice, which are switched to chow diet, an even more pronounced diabetic phenotype, with fasting hyperglycemia, glucose intolerance and insulin resistance, is observed despite a strong and sustained weight loss [77]. The consequences of Endo1 silencing in the ARC of obese mice are therefore intricate. On the one hand, it prevents or reverses the development of obesity while on the other hand, it impairs glucose homeostasis, leading to a dissociation between obesity and T2D (Fig. 2c). Endo1 is not only a protein regulating intracellular ObR trafficking, but it also participates directly in the regulation of ObR signaling. The alteration of Endol expression levels in the ARC neurons could trigger leptin-biased signaling, which impairs the balance between two ObR signaling pathways, and ultimately elicits diabetes without obesity.

\section{The Debate on Leptin Resistance}

\section{Challenging the View of Leptin Resistance}

Leptin resistance is characterized by the failure of elevated endogenous leptin as well as exogenous leptin to 
decrease FI and BW in DIO rodents or humans [44, 45]. However, a recent study in which intraperitoneal injection of an $\mathrm{ObRb}$ antagonist increased FI and BW, in a similar manner between lean and DIO mice, challenged this classical view of leptin resistance [43].

Ottaway et al. [43] suggested that the maintenance of endogenous leptin signaling in DIO rodents would still restrain FI and BW in obesity. The increased basal levels of STAT3 phosphorylation, displayed by DIO rodents in hypothalamic nuclei and especially in the ARC, were proposed to support this notion of increased endogenous leptin-mediated STAT3 signaling in response to elevated endogenous leptin [78]. The interesting observation of augmented basal STAT3 activity in DIO could also result from potential ligand independent activity of ObR that would be sensitive to the blockage by a receptor antagonist. Furthermore, upon HFD challenge, numerous events trigger metabolic changes that could in fine increase basal pSTAT3 levels in the ARC independently of leptin action. For instance, central chronic inflammation and gliosis are associated with increased hypothalamic IL-6 levels $[79,80]$, and IL-6 is known to activate the STAT3 pathway $[81,82]$. Low expression of ObRb at the plasma membrane in DIO, with a subsequent decreased response to leptin, and the higher basal STAT3 activation in the ARC of DIO mice likely involve parallel and independent mechanisms.

Leptin sensitivity/resistance at the cellular level is usually assessed by the ability/inability of leptin to induce STAT3 phosphorylation in neurons. Indeed, since ObRb displays low neuronal expression and transient or weak signaling, the detection of its downstream signaling pathways is difficult in vivo, with the exception of pSTAT3 which is considered to be the canonical marker for $\mathrm{ObRb}$ activation [78]. However, the leptin signaling pathways can be differentially impacted upon HFD, as we observed in our recent study with the striking phenotype of Endo1silenced mice [77], and as observed by others [83] and discussed below. Therefore, the maintenance of endogenous leptin signaling in DIO rodents would require further investigation in order to determine (i) the specific signaling pathways and (ii) the peculiar hypothalamic regions and specialized neurons that can still respond to leptin in HFD conditions.

\section{Selective Leptin Resistance}

By analogy to selective insulin resistance $[84,85]$, the concept of selective leptin resistance emerged with the observation that leptin administration in DIO or genetically obese mice failed to decrease FI and BW (except in the leptin-deficient $o b / o b$ mice) but was still able to increase renal sympathetic nervous system (SNS) activity leading to hypertension [86-88]. Furthermore, the regulation of SNS activity by leptin is differentially impaired in DIO mice. Indeed, while leptin-mediated renal SNS activity is preserved, the increase in SNS outputs towards the brown adipose tissue by leptin is altered in DIO mice [87]. Selective leptin resistance would lead to a failure of leptin to elicit its favorable metabolic actions (FI, BW, thermogenesis regulation), combined with the deleterious maintenance of other leptin actions, such as the regulation of renal SNS activity resulting in hypertension [87, 89].

The mechanisms of selective leptin resistance are not completely understood but may be explained by (i) the central distribution of $\mathrm{ObRb}$ with site-specific leptin resistance [51] and/or (ii) the differential activation of leptin signaling pathways $[15,51,90]$. The first point suggests a persistence of leptin sensitivity during DIO in specific brain regions/hypothalamic sites that regulate energy balance and thus that could still be inhibited by an ObR antagonist. This hypothesis would be consistent with the observation of increased FI and BW in DIO after ObR antagonist administration in DIO mice, observed by Ottaway et al. [43]. Regarding the second mechanism, it was proposed that the central PI3K pathway preferentially mediates the control of renal SNS activity by leptin, while the STAT3 and ERK pathways contribute to the regulation of SNS outputs towards the brown adipose tissue $[34,91,92]$. Furthermore, the leptin-induced renal SNS activity was lost in DIO mice only after intracerebroventricular injection of a PI3K antagonist, suggesting the maintenance of the PI3K signaling in these mice characterized by central, and at least partial, resistance to the leptin-mediated STAT3 pathway [83]. Collectively, these studies suggest that the differential impact of HFD on leptin signaling pathways could be the basis of selective leptin resistance. Interestingly, increased Endo1 expression in the ARC of DIO mice [62] seems to trigger such selective leptin resistance, owing to the dual function of Endo1 which leads to (i) biased leptin-induced STAT3 and PI3K pathways and (ii) the dissociation between obesity and T2D [77]. Furthermore, Endo1-mediated biased leptin signaling in the ARC upon HFD could also contribute to the deleterious overactivation of the renal SNS by leptin, via the maintenance of the PI3K pathway.

\section{Endo1 and Leptin Resistance?}

Endo1 is an accessory protein for ObRb crucial to maintain the appropriate balance between leptin signal- 
ing pathways involved in the regulation of energy and glucose homeostasis [77]. Partial Endol silencing in the ARC leads to an imbalance between JAK2/STAT3 and PI3K/AKT pathways in the hypothalamic neurons of mice challenged with a HFD, possibly favoring the development of T2D [77] (Fig. 2).

Our results raise the question of the contribution of Endo1 in the development of leptin resistance. On the one hand, regarding the trafficking-related function of Endo1, a rise in its level of expression in the ARC upon HFD [62] results in the reduction of ObRb cell surface expression $[56,61]$, leading to decreased neuronal leptin sensitivity. This suggests the importance of Endo1 in the pathophysiology of HFD-induced leptin resistance. On the other hand, low levels of Endo1 in the ARC prevent the leptin-induced PI3K/AKT pathway, contributing to the alteration of glucose homeostasis [77]. The dual role of Endo1, which regulates both ObRb trafficking and its signaling [77], implies its hypothalamic expression being tightly controlled to maintain energy and glucose homeostasis. Although the identity of specific neuronal populations expressing Endo1 has not been characterized thus far, ObR and Endo1, being genetically linked in the human genome, should be expressed in the same neurons. In particular, the expression of Endo1 in specific subpopulations of hypothalamic POMC and AgRP neurons warrants further investigation to dissect the Endo1 impact on the regulation of energy and glucose homeostasis in both neuronal populations.

Modulating Endo1 expression would constitute a valuable therapeutic strategy against obesity if the activation of the JAK2/STAT3 and PI3K/AKT pathways by leptin is appropriately balanced in the ARC. In addition, Endo1 is ubiquitously expressed in other hypothalamic and extrahypothalamic areas as well as in peripheral metabolic tissues such as the liver, skeletal muscle and adipose tissues. The contribution of Endol outside the ARC to maintain energy and glucose homeostasis warrants further investigation in order to determine whether Endo1 would be a relevant therapeutic target.

\section{Acknowledgments}

This work was supported by grants from the European Union's Seventh Framework Programme FP7/2007-2013 (to J.D., R.J.), the "Agence Nationale de la Recherche" ANR-12-JSV1-0011 (to J.D.), ANR-15-CE14-0025 (to J.D. and R.J.), the French "Ministère de l'Education Nationale et de la Recherche en Technologie" (MNERT, ED419) (to C.R.) and the "Fondation pour la Recherche Médicale" (to C.R.).

\section{Disclosure Statement}

The authors declare no competing financial interests.

\section{References}

1 Afshin A, Forouzanfar MH, Reitsma MB, Sur P, Estep K, Lee A, et al.; GBD 2015 Obesity Collaborators. Health Effects of Overweight and Obesity in 195 Countries over 25 Years. N Engl J Med. 2017 Jul;377(1):13-27.

2 Zhang Y, Proenca R, Maffei M, Barone M, Leopold L, Friedman JM. Positional cloning of the mouse obese gene and its human homologue. Nature. 1994 Dec;372(6505):42532.

3 Farooqi IS, Jebb SA, Langmack G, Lawrence E, Cheetham CH, Prentice AM, et al. Effects of recombinant leptin therapy in a child with congenital leptin deficiency. N Engl J Med. 1999 Sep;341(12):879-84.

4 Pelleymounter MA, et al. Effects of the obese gene product on body weight regulation in ob/ob mice. Science. 1995 [Online] [cited 2014 July 8]. Available from: http:// www.Sciencemag.org.gate2.inist.fr/content/269/5223/540.long.

5 Ramachandrappa S, Farooqi IS. Genetic approaches to understanding human obesity. J Clin Invest. 2011 Jun;121(6):2080-6.
6 Considine RV, Sinha MK, Heiman ML, Kriauciunas A, Stephens TW, Nyce MR, et al. Serum immunoreactive-leptin concentrations in normal-weight and obese humans. N Engl J Med. 1996 Feb;334(5):292-5.

7 Mercer JG, Hoggard N, Williams LM, Lawrence CB, Hannah LT, Trayhurn P. Localization of leptin receptor mRNA and the long form splice variant (Ob-Rb) in mouse hypothalamus and adjacent brain regions by in situ hybridization. FEBS Lett. 1996 Jun;387(2-3): 113-6.

8 Balland E, Dam J, Langlet F, Caron E, Steculorum S, Messina A, et al. Hypothalamic tanycytes are an ERK-gated conduit for leptin into the brain. Cell Metab. 2014 Feb;19(2):293301.

9 Cheung CC, Clifton DK, Steiner RA. Proopiomelanocortin neurons are direct targets for leptin in the hypothalamus. Endocrinology. 1997 Oct;138(10):4489-92.
10 Baskin DG, Breininger JF, Schwartz MW. Leptin receptor mRNA identifies a subpopulation of neuropeptide $Y$ neurons activated by fasting in rat hypothalamus. Diabetes. 1999 Apr;48(4):828-33.

11 Betley JN, Cao ZF, Ritola KD, Sternson SM. Parallel, redundant circuit organization for homeostatic control of feeding behavior. Cell. 2013 Dec;155(6):1337-50.

12 Schwartz MW, Woods SC, Porte D Jr, Seeley RJ, Baskin DG. Central nervous system control of food intake. Nature. 2000 Apr; 404(6778):661-71.

13 Scott MM, Lachey JL, Sternson SM, Lee CE, Elias CF, Friedman JM, et al. Leptin targets in the mouse brain. J Comp Neurol. 2009 Jun; 514(5):518-32.

14 Meek TH, Matsen ME, Dorfman MD, Guyenet SJ, Damian V, Nguyen HT, et al. Leptin action in the ventromedial hypothalamic nucleus is sufficient, but not necessary, to normalize diabetic hyperglycemia. Endocrinology. 2013 Sep;154(9):3067-76.
Hypothalamic Endospanin 1 Dissociates Obesity from Type 2 Diabetes
Neuroendocrinology 2019;108:132-141 DOI: $10.1159 / 000494557$ 
15 Enriori PJ, Sinnayah P, Simonds SE, Garcia Rudaz C, Cowley MA. Leptin action in the dorsomedial hypothalamus increases sympathetic tone to brown adipose tissue in spite of systemic leptin resistance. J Neurosci. 2011 Aug;31(34):12189-97.

16 Ghamari-Langroudi M, Srisai D, Cone RD. Multinodal regulation of the arcuate/paraventricular nucleus circuit by leptin. Proc Natl Acad Sci USA. 2011 Jan;108(1):355-60.

17 Bagnasco M, Dube MG, Katz A, Kalra PS, Kalra SP. Leptin expression in hypothalamic PVN reverses dietary obesity and hyperinsulinemia but stimulates ghrelin. Obes Res. 2003 Dec;11(12):1463-70.

18 Leshan RL, Björnholm M, Münzberg H, Myers MG Jr. Leptin receptor signaling and action in the central nervous system. Obesity (Silver Spring). 2006 Aug;14 Suppl 5:208S$12 \mathrm{~S}$.

19 Elmquist JK, Biørbaek C, Ahima RS, Flier JS, Saper CB. Distributions of leptin receptor mRNA isoforms in the rat brain. J Comp Neurol. 1998 Jun;395(4):535-47.

20 Grill HJ, Schwartz MW, Kaplan JM, Foxhall JS, Breininger J, Baskin DG. Evidence that the caudal brainstem is a target for the inhibitory effect of leptin on food intake. Endocrinology. 2002 Jan;143(1):239-46.

21 Hayes MR, Skibicka KP, Leichner TM, Guarnieri DJ, DiLeone RJ, Bence KK, et al. Endogenous leptin signaling in the caudal nucleus tractus solitarius and area postrema is required for energy balance regulation. Cell Metab. 2010 Jan;11(1):77-83.

22 Hommel JD, Trinko R, Sears RM, Georgescu D, Liu ZW, Gao XB, et al. Leptin receptor signaling in midbrain dopamine neurons regulates feeding. Neuron. 2006 Sep;51(6):801-10.

23 Matheny M, Strehler KY, King M, Tümer N, Scarpace PJ. Targeted leptin receptor blockade: role of ventral tegmental area and nucleus of the solitary tract leptin receptors in body weight homeostasis. J Endocrinol. 2014 Jul; 222(1):27-41.

24 Kim JG, Suyama S, Koch M, Jin S, ArgenteArizon P, Argente J, et al. Leptin signaling in astrocytes regulates hypothalamic neuronal circuits and feeding. Nat Neurosci. 2014 Jul; 17(7):908-10.

25 Djogo T, Robins SC, Schneider S, Kryzskaya D, Liu X, Mingay A, et al. Adult NG2-Glia Are Required for Median Eminence-Mediated Leptin Sensing and Body Weight Control. Cell Metab. 2016 May;23(5):797-810.

26 Couturier C, Jockers R. Activation of the leptin receptor by a ligand-induced conformational change of constitutive receptor $\mathrm{di}$ mers. J Biol Chem. 2003 Jul;278(29):2660411.

27 Biener E, Charlier M, Ramanujan VK, Daniel N, Eisenberg A, Bjørbaek C, et al. Quantitative FRET imaging of leptin receptor oligomerization kinetics in single cells. Biol Cell. 2005 Dec;97(12):905-19.
28 Bates SH, Stearns WH, Dundon TA, Schubert $\mathrm{M}$, Tso AW, Wang Y, et al. STAT3 signalling is required for leptin regulation of energy balance but not reproduction. Nature. 2003 Feb; 421(6925):856-9.

29 Bates SH, Dundon TA, Seifert M, Carlson M Maratos-Flier E, Myers MG Jr. LRb-STAT3 signaling is required for the neuroendocrine regulation of energy expenditure by leptin. Diabetes. 2004 Dec;53(12):3067-73.

30 Bates SH, Kulkarni RN, Seifert M, Myers MG Jr. Roles for leptin receptor/STAT3-dependent and -independent signals in the regulation of glucose homeostasis. Cell Metab. 2005 Mar;1(3):169-78.

31 Duan C, Li M, Rui L. SH2-B promotes insulin receptor substrate 1 (IRS1)- and IRS2-mediated activation of the phosphatidylinositol 3-kinase pathway in response to leptin. J Biol Chem. 2004 Oct;279(42):43684-91.

32 Morton GJ, Gelling RW, Niswender KD, Morrison CD, Rhodes CJ, Schwartz MW. Leptin regulates insulin sensitivity via phosphatidylinositol-3-OH kinase signaling in mediobasal hypothalamic neurons. Cell Metab. 2005 Dec;2(6):411-20.

33 Roman EA, Reis D, Romanatto T, Maimon D, Ferreira EA, Santos GA, et al. Central leptin action improves skeletal muscle AKT, AMPK, and PGC1 alpha activation by hypothalamic PI3K-dependent mechanism. Mol Cell Endocrinol. 2010 Jan;314(1):62-9.

34 Rahmouni K, Sigmund CD, Haynes WG, Mark AL. Hypothalamic ERK mediates the anorectic and thermogenic sympathetic effects of leptin. Diabetes. 2009 Mar;58(3):53642.

35 Minokoshi Y, Alquier T, Furukawa N, Kim YB, Lee A, Xue B, et al. AMP-kinase regulates food intake by responding to hormonal and nutrient signals in the hypothalamus. Nature. 2004 Apr;428(6982):569-74.

36 Tanida M, Yamamoto N, Shibamoto T, Rahmouni K. Involvement of hypothalamic AMP-activated protein kinase in leptin-induced sympathetic nerve activation. PLoS One. 2013;8(2):e56660.

37 Bjorbak C, Lavery HJ, Bates SH, Olson RK, Davis SM, Flier JS, et al. SOCS3 mediates feedback inhibition of the leptin receptor via Tyr985. J Biol Chem. 2000 Dec;275(51): 40649-57.

38 Zabolotny JM, Bence-Hanulec KK, StrickerKrongrad A, Haj F, Wang Y, Minokoshi Y, et al. PTP1B regulates leptin signal transduction in vivo. Dev Cell. 2002 Apr;2(4):489-95.

39 Loh K, Fukushima A, Zhang X, Galic S, Briggs D, Enriori PJ, et al. Elevated hypothalamic TCPTP in obesity contributes to cellular leptin resistance. Cell Metab. 2011 Nov; 14(5): 684-99.

40 Bouret SG, Bates SH, Chen S, Myers MG Jr, Simerly RB. Distinct roles for specific leptin receptor signals in the development of hypothalamic feeding circuits. J Neurosci. 2012 Jan;32(4):1244-52.
41 Rankinen T, Zuberi A, Chagnon YC, Weisnagel SJ, Argyropoulos G, Walts B, et al. The human obesity gene map: the 2005 update. Obesity (Silver Spring). 2006 Apr;14(4):529-644.

42 Maffei M, Halaas J, Ravussin E, Pratley RE, Lee GH, Zhang Y, et al. Leptin levels in human and rodent: measurement of plasma leptin and ob RNA in obese and weight-reduced subjects. Nat Med. 1995 Nov;1(11):1155-61.

43 Ottaway N, Mahbod P, Rivero B, Norman LA, Gertler A, D’Alessio DA, et al. Diet-induced obese mice retain endogenous leptin action. Cell Metab. 2015 Jun;21(6):877-82.

44 Halaas JL, Boozer C, Blair-West J, Fidahusein N, Denton DA, Friedman JM. Physiological response to long-term peripheral and central leptin infusion in lean and obese mice. Proc Natl Acad Sci USA. 1997 Aug;94(16):887883.

45 Myers MG, Cowley MA, Münzberg H. Mechanisms of leptin action and leptin resistance. Annu Rev Physiol. 2008;70(1):537-56.

46 Roujeau C, Jockers R, Dam J. New pharmacological perspectives for the leptin receptor in the treatment of obesity. Front Endocrinol (Lausanne). 2014 Oct;5:167.

47 Banks WA, DiPalma CR, Farrell CL. Impaired transport of leptin across the blood-brain barrier in obesity. Peptides. 1999 Nov;20(11): 1341-5.

48 Caro JF, Kolaczynski JW, Nyce MR, Ohannesian JP, Opentanova I, Goldman WH, et al. Decreased cerebrospinal-fluid/serum leptin ratio in obesity: a possible mechanism for leptin resistance. Lancet. 1996 Jul;348(9021): $159-61$.

49 Schwartz MW, Peskind E, Raskind M, Boyko EJ, Porte D Jr. Cerebrospinal fluid leptin levels: relationship to plasma levels and to adiposity in humans. Nat Med. 1996 May;2(5): 589-93.

50 Enriori PJ, Evans AE, Sinnayah P, Jobst EE, Tonelli-Lemos L, Billes SK, et al. Diet-induced obesity causes severe but reversible leptin resistance in arcuate melanocortin neurons. Cell Metab. 2007 Mar;5(3):181-94.

51 Münzberg H, Flier JS, Bjørbaek C. Regionspecific leptin resistance within the hypothalamus of diet-induced obese mice. Endocrinology. 2004 Nov; 145(11):4880-9.

52 Zhang X, Zhang G, Zhang H, Karin M, Bai H, Cai D. Hypothalamic IKKbeta/NF-kappaB and ER stress link overnutrition to energy imbalance and obesity. Cell. 2008 Oct;135(1): 61-73.

53 Horvath TL, Sarman B, García-Cáceres C, Enriori PJ, Sotonyi P, Shanabrough M, et al. Synaptic input organization of the melanocortin system predicts diet-induced hypothalamic reactive gliosis and obesity. Proc Natl Acad Sci USA. 2010 Aug;107(33):14875-80.

54 Ozcan L, Ergin AS, Lu A, Chung J, Sarkar S, $\mathrm{Nie}$ D, et al. Endoplasmic reticulum stress plays a central role in development of leptin resistance. Cell Metab. 2009 Jan;9(1):35-51. 
55 Diano S, Kalra SP, Horvath TL. Leptin receptor immunoreactivity is associated with the Golgi apparatus of hypothalamic neurons and glial cells. J Neuroendocrinol. 1998 Sep;10(9): 647-50.

56 Couturier C, Sarkis C, Séron K, Belouzard S, Chen P, Lenain A, et al. Silencing of OBRGRP in mouse hypothalamic arcuate nucleus increases leptin receptor signaling and prevents diet-induced obesity. Proc Natl Acad Sci USA. 2007 Dec;104(49):19476-81.

57 Belouzard S, Delcroix D, Rouillé Y. Low levels of expression of leptin receptor at the cell surface result from constitutive endocytosis and intracellular retention in the biosynthetic pathway. J Biol Chem. 2004 Jul;279(27): 28499-508.

58 Vauthier V, Derviaux C, Douayry N, Roux T, Trinquet E, Jockers R, et al. Design and validation of a homogeneous time-resolved fluorescence-based leptin receptor binding assay. Anal Biochem. 2013 May;436(1):1-9.

59 Bailleul B, Akerblom I, Strosberg AD. The leptin receptor promoter controls expression of a second distinct protein. Nucleic Acids Res. 1997 Jul;25(14):2752-8.

60 Vauthier V, Jaillard S, Journel H, Dubourg C, Jockers R, Dam J. Homozygous deletion of an $80 \mathrm{~kb}$ region comprising part of DNAJC6 and LEPR genes on chromosome $1 \mathrm{P} 31.3$ is associated with early onset obesity, mental retardation and epilepsy. Mol Genet Metab. 2012 Jul; 106(3):345-50.

61 Séron K, Couturier C, Belouzard S, Bacart J, Monté D, Corset L, et al. Endospanins regulate a postinternalization step of the leptin receptor endocytic pathway. J Biol Chem. 2011 May;286(20):17968-81.

62 Vauthier V, Swartz TD, Chen P, Roujeau C, Pagnon M, Mallet J, et al. Endospanin 1 silencing in the hypothalamic arcuate nucleus contributes to sustained weight loss of high fat diet obese mice. Gene Ther. 2014 Jul;21(7): 638-44.

63 Forsythe E, Beales PL. Bardet-Biedl syndrome. Eur J Hum Genet. 2013 Jan;21(1):813.

64 Han YM, Kang GM, Byun K, Ko HW, Kim J, Shin MS, et al. Leptin-promoted cilia assembly is critical for normal energy balance. J Clin Invest. 2014 May;124(5):2193-7.

65 Osório J. Cilia length - role in energy balance. Nat Rev Endocrinol. 2014 Jun;10(6):313.

66 Guo DF, Cui H, Zhang Q, Morgan DA, Thedens DR, Nishimura D, et al. The BBSome Controls Energy Homeostasis by Mediating the Transport of the Leptin Receptor to the Plasma Membrane. PLoS Genet. 2016 Feb; 12(2):e1005890

67 Seo S, Guo DF, Bugge K, Morgan DA, Rahmouni K, Sheffield VC. Requirement of Bardet-Biedl syndrome proteins for leptin receptor signaling. Hum Mol Genet. 2009 Apr; 18(7):1323-31.
68 Wauman J, De Ceuninck L, Vanderroost N, Lievens S, Tavernier J. RNF41 (Nrdp1) controls type 1 cytokine receptor degradation and ectodomain shedding. J Cell Sci. 2011 Mar; 124(Pt 6):921-32.

69 De Ceuninck L, Wauman J, Masschaele D, Peelman F, Tavernier J. Reciprocal cross-regulation between RNF41 and USP8 controls cytokine receptor sorting and processing. J Cell Sci. 2013 Aug;126(Pt 16):3770-81.

70 Wijesuriya TM, De Ceuninck L, Masschaele D, Sanderson MR, Carias KV, Tavernier J, et al. The Prader-Willi syndrome proteins MAGEL2 and necdin regulate leptin receptor cell surface abundance through ubiquitination pathways. Hum Mol Genet. 2017 Nov;26(21): 4215-30.

71 Pravdivyi I, Ballanyi K, Colmers WF, Wevrick R. Progressive postnatal decline in leptin sensitivity of arcuate hypothalamic neurons in the Magel2-null mouse model of Prader-Willi syndrome. Hum Mol Genet. 2015 Aug; 24(15):4276-83.

72 Mazor R, et al. Cleavage of the leptin receptor by matrix metalloproteinase- 2 promotes leptin resistance and obesity in mice. Sci Transl Med. 2018 Aug;10(455):eaah6324.

73 Miksztowicz V, Siseles N, Fernandez Machulsky N, Schreier L, Berg G. Increase in MMP-2 activity in overweight and obese women is associated with menopausal status. Climacteric. 2012 Dec;15(6):602-6.

74 Miksztowicz V, Muzzio ML, Royer M, Prada M, Wikinski R, Schreier L, et al. Increased plasma activity of metalloproteinase 2 in women with metabolic syndrome. Metabolism. 2008 Nov;57(11):1493-6.

75 Huang H, Wang W, Tao Y-X. Pharmacological chaperones for the misfolded melanocortin-4 receptor associated with human obesity. Biochim Biophys Acta. 2017 Oct;1863(10, Pt A):2496-2507.

76 Kim TH, Choi DH, Vauthier V, Dam J, Li X, Nam YJ, et al. Anti-obesity phenotypic screening looking to increase OBR cell surface expression. J Biomol Screen. 2014 Jan;19(1): 88-99.

77 Vauthier V, Roujeau C, Chen P, Sarkis C, Migrenne $\mathrm{S}$, Hosoi T, et al. Endospanin 1 affects oppositely body weight regulation and glucose homeostasis by differentially regulating central leptin signaling. Mol Metab. 2016 Nov;6(1):159-72.

78 Pan WW, Myers MG Jr. Leptin and the maintenance of elevated body weight. Nat Rev Neurosci. 2018 Feb;19(2):95-105.

79 De Souza CT, Araujo EP, Bordin S, Ashimine $\mathrm{R}$, Zollner RL, Boschero AC, et al. Consumption of a fat-rich diet activates a proinflammatory response and induces insulin resistance in the hypothalamus. Endocrinology. 2005 Oct;146(10):4192-9.
80 Milanski M, Degasperi G, Coope A, Morari J, Denis R, Cintra DE, et al. Saturated fatty acids produce an inflammatory response predominantly through the activation of TLR4 signaling in hypothalamus: implications for the pathogenesis of obesity. J Neurosci. 2009 Jan; 29(2):359-70.

81 Girotti M, Donegan JJ, Morilak DA. Influence of hypothalamic IL-6/gp130 receptor signaling on the HPA axis response to chronic stress. Psychoneuroendocrinology. 2013 Jul; 38(7):1158-69.

82 Timper K, Denson JL, Steculorum SM, Heilinger C, Engström-Ruud L, Wunderlich CM, et al. IL-6 Improves Energy and Glucose Homeostasis in Obesity via Enhanced Central IL-6 trans-Signaling. Cell Reports. 2017 Apr; 19(2):267-80.

83 Morgan DA, Thedens DR, Weiss R, Rahmouni K. Mechanisms mediating renal sympathetic activation to leptin in obesity. Am J Physiol Regul Integr Comp Physiol. 2008 Dec; 295(6):R1730-6.

84 Brown MS, Goldstein JL. Selective versus total insulin resistance: a pathogenic paradox. Cell Metab. 2008 Feb;7(2):95-6.

85 Otero YF, Stafford JM, McGuinness OP. Pathway-selective insulin resistance and metabolic disease: the importance of nutrient flux. J Biol Chem. 2014 Jul;289(30):20462-9.

86 Rahmouni K, Haynes WG, Morgan DA Mark AL. Selective resistance to central neural administration of leptin in agouti obese mice. Hypertension. 2002 Feb;39(2, Pt 2): 486-90.

87 Rahmouni K, Morgan DA, Morgan GM Mark AL, Haynes WG. Role of selective leptin resistance in diet-induced obesity hypertension. Diabetes. 2005 Jul;54(7):2012-8.

88 Correia ML, Haynes WG, Rahmouni K, Morgan DA, Sivitz WI, Mark AL. The concept of selective leptin resistance: evidence from agouti yellow obese mice. Diabetes. $2002 \mathrm{Feb}$; 51(2):439-42.

89 Mark AL. Selective leptin resistance revisited. Am J Physiol Regul Integr Comp Physiol. 2013 Sep;305(6):R566-81.

90 Faouzi M, Leshan R, Björnholm M, Hennessey T, Jones J, Münzberg H. Differential accessibility of circulating leptin to individual hypothalamic sites. Endocrinology. 2007 Nov; 148(11):5414-23.

91 Harlan SM, Guo DF, Morgan DA, FernandesSantos C, Rahmouni K. Hypothalamic mTORC1 signaling controls sympathetic nerve activity and arterial pressure and mediates leptin effects. Cell Metab. 2013 Apr;17(4): 599-606.

92 Harlan SM, Morgan DA, Dellsperger DJ, Myers MG Jr, Mark AL, Rahmouni K. Cardiovascular and sympathetic effects of disrupting tyrosine 985 of the leptin receptor. Hypertension. 2011 Mar;57(3):627-32. 